\title{
Neutrophil-activating Peptide-1/Interleukin 8, a Novel Cytokine That Activates Neutrophils
}

\author{
Marco Baggiolini, * Alfred Walz, * and Steven L. Kunkel ${ }^{\star}$ \\ ${ }^{*}$ Theodor-Kocher Institute, University of Bern, Bern, Switzerland; and ${ }^{\ddagger}$ Department of Pathology, \\ The University of Michigan Medical School, Ann Arbor, Michigan 48109
}

\section{Introduction}

Neutrophil accumulation in a tissue is characteristic of inflammation and is observed in a variety of pathological conditions as disparate as infection, trauma, ischemia, and cancer. The process of tissue infiltration is best understood in bacterial infection, where neutrophils are selectively attracted in large numbers to phagocytose and kill the invaders. In other conditions neutrophils are presumably recruited as scavengers of damaged tissue or unwanted extracellular deposits like immune complexes or fibrin. Phagocytosis is accompanied by the release of granule enzymes, superoxide, $\mathrm{H}_{2} \mathrm{O}_{2}$, and a variety of bioactive lipids. Several of these products are required for the killing and digestion of microorganisms. They also induce inflammation and tissue damage, however, which is normally observed after neutrophil accumulation.

Several neutrophil chemoattractants have been characterized in recent years; the best known are the anaphylatoxin C5a (1), formylmethionyl peptides of bacterial origin (2), plateletactivating factor (PAF; 3$),{ }^{1}$ and leukotriene $\mathrm{B}_{4}\left(\mathrm{LTB}_{4} ; 4\right)$. These stimuli have different origins and modes of formation, and their occurrence in disease must thus be expected to vary in accord with the underlying pathophysiological process. C5a is formed upon complement activation via the classical pathway after interaction of microorganisms with antibodies or the formation of immune complexes, or via the alternative pathway after the nonimmune recognition of foreign materials. In bacterial infections, on the other hand, formylmethionyl peptides (which are released by the microorganisms) are likely to be the major attractants. PAF and $\mathrm{LTB}_{4}$ are of special interest because they can be generated by the neutrophils themselves and may thus function as auto- or paracrine amplifiers of the responses elicited by other stimuli (5). It has been shown that C5a, formylmethionyl peptides, PAF, and $\mathrm{LTB}_{4}$ act via unrelated receptors, suggesting that neutrophil recruitment can result from the concerted action of multiple stimuli.

Address correspondence to Dr. Marco Baggiolini, Theodor-Kocher Institute, P.O. Box 99, CH-3000 Bern 9, Switzerland.

Received for publication 18 May 1989.

1. Abbreviations used in this paper: B-TG, beta thromboglobulin; MIP, macrophage inflammatory protein; NAF, neutrophil-activating factor; NAP, neutrophil-activating peptide; PAF, platelet-activating factor; PBP, platelet basic protein; TNF, tumor necrosis factor.

J. Clin. Invest.

(C) The American Society for Clinical Investigation, Inc.

0021-9738/89/10/1045/05 \$2.00

Volume 84, October 1989, 1045-1049
Here we review recent findings demonstrating the existence of a novel tissue-derived neutrophil-activating peptide (NAP) secreted by several types of cells in response to inflammatory stimuli. The new peptide was called MDNCF for monocyte-derived neutrophil chemotactic factor (6), MONAP for monocyte-derived NAP (7), and NAF for neutrophil-activating factor (8) by the groups initially involved in this work. Still other names were used in later reports. The terms NAP-1 and IL-8 were subsequently proposed $(9,10)$, and NAP-1/IL-8 will thus be used.

\section{Neutrophil activation by chemotactic agonists}

Neutrophils exposed to chemotactic stimuli marginate, adhere to the endothelial cells, and migrate into the extravascular space. Several functional responses including shape change, adherence, directed movement, enzyme secretion, and the respiratory burst are observed in vitro after stimulation. All responses are initiated by the binding of the agonist to its receptor and the subsequent interaction of the agonist-receptor complex with a GTP-binding protein (11). This event stimulates phosphatidyl inositol hydrolysis by a phospholipase $\mathrm{C}$ that yields inositol phosphates and diacylglycerol (12), and leads to a transient rise in cytosolic free calcium (13) and the activation of protein kinase $C(14)$. The entire reaction cascade is considered to be part of the signal transduction process.

\section{Structure of NAP-1/IL-8}

Purification and sequencing of the material obtained in the culture supernatants of stimulated human blood mononuclear phagocytes showed that NAP-1/IL-8 has no significant homology with other cytokines produced by these cells, including IL-1, tumor necrosis factor (TNF), colony-stimulating factors, and IFNs $(6,15)$. NAP-1/IL-8 is generated as a 99-amino acid precursor with a characteristic leader sequence of 22 amino acids $(16,17)$. Several mature forms have been identified $(15$, $18,19)$, suggesting that NAP-1/IL-8 is processed by repeated amino-terminal cleavage. The major form, which consists of 72 amino acids, has been obtained by recombinant methodology using a synthetic gene expressed in Escherichia coli (15).

NAP-1/IL-8 has considerable sequence homology with peptides from platelet alpha granules such as platelet basic protein (PBP) (20), connective tissue activating peptide III (21), and platelet factor 4 (22). In addition, NAP-1/IL-8 has structural and biological similarities with a recently discovered macrophage inflammatory protein 2 (MIP-2) (23) which could represent the murine homologue to NAP-1/IL-8. As shown in Fig. 1, the relative positions of the four cysteine residues of these peptides are virtually identical. After release from the alpha granules, PBP and connective tissue activating peptide 
III are cleaved to yield beta thromboglobulin (B-TG) (24) and, apparently, even smaller derivatives. A 70-amino acid cleavage product of PBP was recently isolated from cultures of stimulated human blood mononuclear cells and called NAP-2 because of its neutrophil-activating properties which are similar to those of NAP-1/IL-8 (25). Two proteins obtained from human cell lines, gamma-IP-10 (26) and gro (27) or melanoma growth stimulatory factor (28) also belong to this family of peptides on the basis of their structural homology. Their biological activities, however, have not been elucidated in detail. It has been shown that the cysteine residues of NAP-1/IL-8 form disulfide bridges that are essential for activity (29). Like B-TG, NAP-1/IL-8 probably has a two-loop configuration resulting from the linkage of the first to the third and the second to the fourth cysteine (24). In all peptides described, the two first cysteines are separated by one amino acid. This feature distinguishes them from a group of homologues with two adjacent cysteines comprising the murine MIP-1 (30, 31), and recently reported peptides that are chemotactic for human monocytes $(32,33)$ and thus appear to have biological properties that differ significantly from those of NAP-1/IL-8.

\section{Biological properties of NAP-1/IL-8}

Comparative studies have shown that the biological profile of activity of NAP-1/IL-8 is very similar to that of the classical chemotactic peptides $\mathrm{C} 5 \mathrm{a}$ and $\mathrm{f}-\mathrm{Met}-\mathrm{Leu}-\mathrm{Phe}$. As summarized in Table I, NAP-1/IL-8 induces the full pattern of responses observed in chemotactically stimulated neutrophils, i.e., activation of the motile apparatus and directional migration, expression of surface adhesion molecules, release of storage enzymes, and production of reactive oxygen metabolites. Real time recordings show that the responses are transient, as with other chemotactic agonists $(29,34)$. The similarity extends to the mechanism of signal transduction. NAP-1/IL-8 elicits a rapid and transient rise in cytosolic free calcium $(29,34)$. All NAP-1/IL-8-mediated responses, including the calcium changes, are prevented by pretreatment of the cells with Bordetella pertussis toxin, indicating that signal transduction depends on a GTP-binding protein (34). The respiratory burst induced by NAP-1/IL- 8 is inhibited by staurosporine, implying a role for protein kinase C, and by wortmannin (34), a fungal metabolite that blocks certain agonist responses by interfering with a calcium-independent signal transduction pathway (35). Desensitization experiments with C5a, f-Met-
Leu-Phe, PAF, and $\mathrm{LTB}_{4}$ suggest that NAP-1/IL-8 acts via a selective receptor $(7,29)$. It was recently reported that neutrophils have on average 20,000 NAP-1/IL- 8 receptors with a $K_{d}$ of $8 \times 10^{-10} \mathrm{M}$ (36). Studies by Besemer et al. (37) indicate the existence of $\sim 5,000$ high-affinity $\left(K_{d}=1-3 \times 10^{-11} \mathrm{M}\right)$ and $30,000-40,000$ low-affinity $\left(K_{d}=6-8 \times 10^{-10} \mathrm{M}\right)$ binding sites per cell. Similar densities but lower affinities were reported previously for f-Met-Leu-Phe $(38,39)$ and C5a $(40,41)$ receptors.

The effects of C5a, f-Met-Leu-Phe, PAF, and $\mathrm{LTB}_{4}$ are not restricted to neutrophils. Monocytes and other granulocytes respond to these stimuli as well, and PAF has an even wider range of activities. By comparison, NAP-1/IL-8 appears to be more selective: it does not stimulate mononuclear phagocytes or platelets (34), and has only borderline effects on eosinophils (7) and basophils from normal and atopic individuals (42). NAP-1/IL-8 was reported to be chemotactic for lymphocytes (9). Human blood lymphocytes show no cytosolic free calcium changes upon stimulation with NAF/NAP-1 (34). Low levels of specific binding of ${ }^{125}$ I-labeled NAF/NAP-1 are found with blood lymphocytes and monocytes separated by elutriation. These cell preparations, however, are not completely pure, and binding by contaminating cells cannot be excluded (37).

NAP-1/IL-8 is not species specific, and its effects in vivo could thus be studied in several laboratory animals. Injection into the skin of rabbits results in plasma exudation and a massive neutrophil infiltration. The effect is long lasting and no other cells beside neutrophils can be detected, underlining the target selectivity of the stimulus (43). Similar, but less severe and more transient lesions are obtained with f-Met-LeuPhe or E. coli LPS. Massive neutrophil infiltration is also observed upon intradermal injection of NAP-1/IL-8 in rats, mice, guinea pigs, and dogs (Zwahlen, R., I. Colditz, and M. Baggiolini, manuscript in preparation). The long duration of action could be due to the remarkable resistance of NAP-1/ IL- 8 to inactivation by plasma peptidases and its low rate of degradation by proteases (29).

\section{NAP-1/IL-8 is a product of many cells}

As several independent laboratories originally described NAP-1/IL-8 as a product of mononuclear phagocytes $(6-8,29$, $44)$, it was interesting to find that the same peptide is expressed in wide variety of cells after appropriate stimulation. Fibroblasts (45), epithelial cells (46), and hepatocytes (46) express NAP-1/IL-8 mRNA in response to IL-1-alpha, IL-1-beta, and

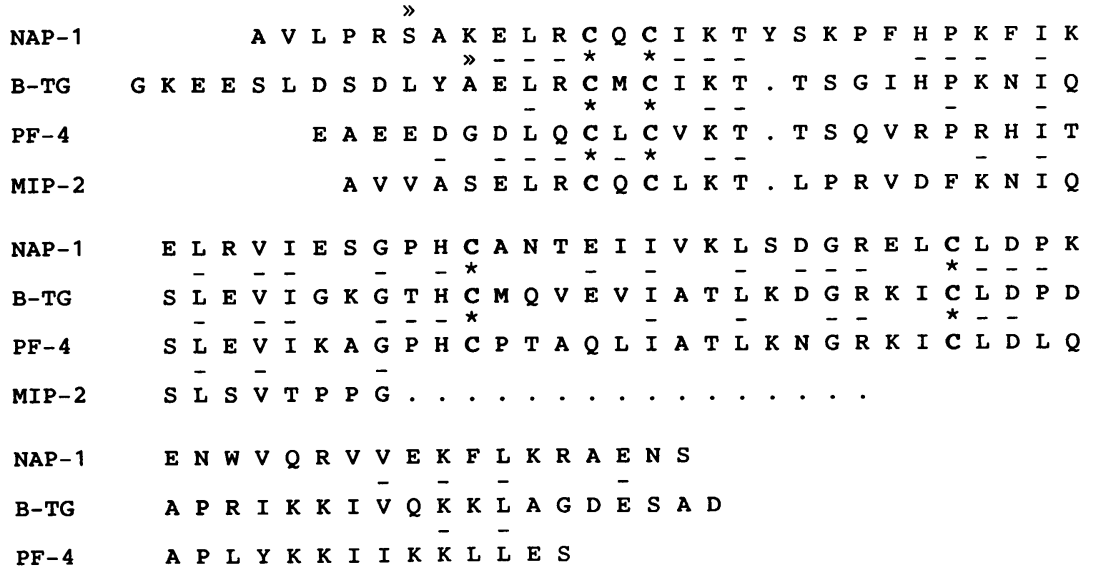

Figure 1. Sequences of NAP-1/IL-8, the PBP cleavage product beta thromboglobulin ( $B-T G)$, platelet factor $4(P F-4)$, and MIP-2 aligned according to their four cysteines $\left(^{*}\right)$. Hyphens above symbols indicate amino acids that correspond to those of the NAP-1/IL-8 sequence. The largest mature NAP-1/IL-8 form (77 amino acids) is shown. The amino-terminal serine of the main form (72 amino acids) is indicated ( $\gg$ ). PBP is 13 residues longer than $B-T G$. The amino terminus of NAP-2 is indicated above the B-TG sequence $(\gg)$. 
Table I. Effects of NAP-1/IL-8 on Human Neutrophils

\begin{tabular}{lll}
\multicolumn{1}{c}{ Response } & \multicolumn{1}{c}{ Detection } & References \\
\hline Chemotaxis & Boydens' chamber & 6,7 \\
& & 15 \\
Shape change & Laser turbidimetry & 34 \\
Exocytosis of: & Release of: & \\
\multicolumn{1}{c}{ Secretory vesicles } & Gelatinase* & \\
Specific granules & Vitamin $\mathrm{B}_{12}$-binding protein & 29 \\
Azurophil granules & Beta glucuronidase, elastase & $7,29,34$ \\
Receptor expression & $\mathrm{CD}_{11 \mathrm{~b}} / \mathrm{CD}_{18}$ & 66 \\
Respiratory burst $\left.\mathrm{Ca}^{2+}\right]_{\mathrm{i}}$ rise & Production of $\mathrm{O}_{2}^{-}$and $\mathrm{H}_{2} \mathrm{O}_{2}$ & 29,34 \\
& Quin-2 fluorescence & 29,34
\end{tabular}

* Morel, F., and B. Dewald, unpublished observations.

TNF-alpha, while in monocytes $(29,47)$, alveolar macrophages (48), and endothelial cells (48-50) expression can be induced in addition with LPS (Table II). On the other hand, no NAP-1/IL-8 generation is observed upon stimulation with IL-6 (49), IL-2, and type I or II IFNs (Peveri, P., A. Walz, and M. Baggiolini, unpublished observations). In alveolar macrophages, monocytes, and endothelial cells cultured in the presence of LPS, TNF, or IL-1, expression is very rapid. Using a labeled 30-mer oligonucleotide (5'-GTT-GGC-GCA-GTGTGG-TCC-ACT-CTC-AAT-CAC-3') or NAP-1/IL-8 cDNA prepared from TNF-stimulated cells, specific mRNA can be detected on Northern blots within $1 \mathrm{~h}$. The maximum is reached at $\sim 6 \mathrm{~h}$ and high levels are still detectable at $24 \mathrm{~h} \mathrm{(48,}$ 51). Treatment of endothelial cells with cycloheximide before stimulation shows that NAP-1/IL-8 mRNA is superinducible, suggesting that gene expression does not depend on the synthesis of other cellular proteins and may be under the control of a repressor protein (46). The persistence of NAP-1/IL-8 mRNA, which is also observed in stimulated fibroblasts, epithelial cells, and hepatocytes $(45,46)$, contrasts with the transient appearance of mRNA coding for other cytokines, e.g., TNF (52).

\section{$N A P-1 / I L-8$ in health and disease}

The involvement of NAP-1/IL-8 in disease is suggested by the demonstration of its occurrence in the skin lesions of patients with psoriasis (53). Such lesions also contain high levels of IL-1 that could function as inducer. NAP-1/IL-8 may also be involved in arthritis, since it has been shown that IL-1-stimulated synovial cells produce a NAF (54). In rheumatoid arthritis and other inflammatory joint diseases NAP-1/IL-8 could

Table II. Stimulus-dependent Generation of NAP-1/IL-8 mRNA

\begin{tabular}{lccccc}
\hline \multicolumn{1}{c}{ Cell } & \multicolumn{5}{c}{ Stimulus } \\
\cline { 2 - 6 } \multicolumn{1}{c}{ None } & LPS & TNF & IL-1 & IL-6 \\
\hline Blood monocytes & - & +++ & +++ & +++ & \\
Alveolar macrophages & $(+)$ & +++ & +++ & +++ & \\
Endothelial cells & - & +++ & +++ & +++ & - \\
Fibroblasts & - & - & +++ & +++ & - \\
Epithelial cells & - & - & +++ & +++ & - \\
Hepatoma cells & - & - & +++ & +++ & \\
\hline
\end{tabular}

See text for references. bring about the accumulation of neutrophils, which are considered a major source of cartilage-degrading enzymes (55). Neutrophil accumulation is an important pathogenic event in the lung. Idiopathic pulmonary fibrosis and asbestosis are characterized by a massive, selective recruitment of neutrophils into the alveolar space leading to lung parenchymal cell injury and the breakdown of interstitial structures $(56,57)$. Neutrophils are also preponderant in adult respiratory distress syndrome, where extensive tissue damage is attributed to elastase and other neutral proteases released from the azurophil granules (58-60). Chemotactic factor(s) with high selectivity for neutrophils are likely to be involved in these diseases, and the search for NAP-1/IL-8 expression and release may lead to a better understanding of the underlying pathophysiological process. This appears particularly important in adult respiratory distress syndrome, where enhanced levels of a peptide with the characteristics of NAP-1/IL- 8 have been detected in the bronchoalveolar lavage fluid (61). By contrast, C5a, C5adesArg, or cleavage products of $\mathrm{C} 3$, fibrinogen, and fibronectin could be ruled out as causative agents (60).

Further information on the pathophysiological functions of NAP-1/IL-8 will be gained through studies on the production of this mediator in normal and diseased tissues. Its widespread expression in response to IL-1 and TNF is remarkable and suggests that NAP-1/IL-8 may represent a ubiquitous neutrophil attractant formed upon disturbance of tissue homeostasis. For instance, NAP-1/IL-8 could cause the infiltration of neutrophils around myocardial infarction areas and thus contribute to the reperfusion damage associated with inflammatory cell products (62). Under physiological conditions NAP-1/IL-8 may function as an attractant for the steady emigration of neutrophils from the blood to the tissue compartment that drives turnover. High numbers of neutrophils are eliminated across the epithelial barrier of the gastrointestinal tract (63). Like type II alveolar cells (46), other cells derived from the embryonic endoderm, including the gastrointestinal epithelium, may in fact have the capacity to synthesize NAP-1/IL-8. A key role in NAP-1/IL-8-dependent neutrophil emigration is presumably played by the venular endothelium. Upon stimulation with IL-1 or TNF, endothelial cells express adhesion proteins $(64,65)$ that promote their interaction with circulating neutrophils, and release NAP-1/IL-8 as a stimulus of migration. Thus they appear to be particularly suited for the focal recruitment of neutrophils at inflamed sites.

The emerging understanding of the potential role of NAP-1/IL-8 in inflammation may offer a new basis for the design of antiinflammatory agents conceived as antagonists or inhibitors of the synthesis of the novel mediator.

\section{Acknowledgments}

We thank Dr. Beatrice Dewald and Dr. Ian Colditz for critical reading of the manuscript, and Sabine Imer for editorial assistance.

This study was supported in part by the Swiss National Science Foundation, grant 31-25700.88, and the Foundation Jean \& Linette Warnery, Morges, Switzerland.

Note added in proof. Recent studies have shown that human blood basophil leukocytes become sensitive to NAP-1/IL-8 after pretreatment with IL-3. Basophils exposed in vitro to IL-3 $(1-20 \mathrm{ng} / \mathrm{ml})$ for 5 min at $37^{\circ} \mathrm{C}$ responded to NAP-1/IL-8 in a concentration-dependent manner, releasing histamine and sulfidoleukotrienes (67). 


\section{References}

1. Fernandez, H. N., P. M. Henson, A. Otani, and T. E. Hugli. 1978. Chemotactic response to human $\mathrm{C} 3 \mathrm{a}$ and $\mathrm{C} 5 \mathrm{a}$ anaphylatoxins. I. Evaluation of C3a and C5a leukotaxis in vitro and under stimulated in vivo conditions. J. Immunol. 120:109-115.

2. Schiffmann, E., B. A. Corcoran, and S. M. Wahl. 1975. $N$-formylmethionyl peptides as chemoattractants for leucocytes. Proc. Natl. Acad. Sci. USA. 72:1059-1062.

3. Lee, T. C., and F. Snyder. 1985. Function, metabolism and regulation of platelet activating factor and related ether lipids. In Phospholipids and cellular Regulation. J. F. Kuo, editor. CRC Press, Inc., Boca Raton. 1-39.

4. Ford Hutchinson, A. W., M. A. Bray, M. V. Doig, M. E. Shipley, and M. J. Smith. 1980. Leukotriene B, a potent chemokinetic and aggregating substance released from polymorphonuclear leukocytes. Nature (Lond.). 286:264-265.

5. Baggiolini, M., B. Dewald, and M. Thelen. 1988. Effects of PAF on neutrophils and mononuclear phagocytes. Prog. Biochem. Pharmacol. 22:90-105.

6. Yoshimura, T., K. Matsushima, S. Tanaka, E. A. Robinson, E. Appella, J. J. Oppenheim, and E. J. Leonard. 1987. Purification of a human monocyte-derived neutrophil chemotactic factor that has peptide sequence similarity to other host defense cytokines. Proc. Natl. Acad. Sci. USA. 84:9233-9237.

7. Schroeder, J. M., U. Mrowietz, E. Morita, and E. Christophers. 1987. Purification and partial biochemical characterization of a human monocyte-derived, neutrophil-activating peptide that lacks interleukin 1 activity. J. Immunol. 139:3474-3483.

8. Walz, A., P. Peveri, H. Aschauer, and M. Baggiolini. 1987. Purification and amino acid sequencing of NAF, a novel neutrophilactivating factor produced by monocytes. Biochem. Biophys. Res. Commun. 149:755-761.

9. Larsen, C. G., A. O. Anderson, E. Appella, J. J. Oppenheim, and K. Matsushima. 1989. The neutrophil-activating protein (NAP-1) is also chemotactic for T lymphocytes. Science (Wash. DC). 243:14641466.

10. Westwick, J., S. W. Li, and R. D. Camp. 1989. Novel neutrophil-stimulating peptides. Immunol. Today. 10:146-147.

11. Smith, C. D., C. C. Cox, and R. Snyderman. 1986. Receptorcoupled activation of phosphoinositide-specific phospholipase $\mathrm{C}$ by an N protein. Science (Wash. DC). 232:97-100.

12. Berridge, M. J., and R. F. Irvine. 1984. Inositol trisphosphate, a novel second messenger in cellular signal transduction. Nature (Lond.). 312:315-321.

13. Pozzan, T., D. P. Lew, C. B. Wollheim, and R. Y. Tsien. 1983. Is cytosolic ionized calcium regulating neutrophil activation. Science (Wash. DC). 221:1413-1415.

14. Tauber, A. I. 1987. Protein kinase $C$ and the activation of the human neutrophil NADPH-oxidase. Blood. 69:711-720.

15. Lindley, I., H. Aschauer, J. M. Seifert, C. Lam, W. Brunowsky, E. Kownatzki, M. Thelen, P. Peveri, B. Dewald, V. von Tscharner, A. Walz, and M. Baggiolini. 1988. Synthesis and expression in Escherichia coli of the gene encoding monocyte-derived neutrophil-activating factor: biological equivalence between natural and recombinant neutrophil-activating factor. Proc. Natl. Acad. Sci. USA. 85:91999203.

16. Schmid, J., and C. Weissmann. 1987. Induction of mRNA for a serine protease and a beta-thromboglobulin-like protein in mitogenstimulated human leukocytes. J. Immunol. 139:250-256.

17. Matsushima, K., K. Morishita, T. Yoshimura, S. Lavu, Y. Kobayashi, W. Lew, E. Appella, H. F. Kung, E. J. Leonard, and J. J. Oppenheim. 1988. Molecular cloning of a human monocyte-derived neutrophil chemotactic factor (MDNCF) and the induction of MDNCF mRNA by interleukin 1 and tumor necrosis factor. J. Exp. Med. 167:1883-1893.

18. Gregory, H., J. Young, J. M. Schroeder, U. Mrowietz, and E. Christophers. 1988. Structure determination of a human lymphocyte derived neutrophil activating peptide (LYNAP). Biochem. Biophys. Res. Commun. 151:883-890.

19. Yoshimura, T., E. A. Robinson, E. Appella, K. Matsushima, S. D. Showalter, A. Skeel, and E. J. Leonard. 1989. Three forms of monocyte-derived neutrophil chemotactic factor (MDNCF) distinguished by different lengths of the amino-terminal sequence. $\mathrm{Mol}$. Immunol. 26:87-93.

20. Holt, J. C., M. E. Harris, A. M. Holt, E. Lange, A. Henschen, and S. Niewiarowski. 1986. Characterization of human platelet basic protein, a precursor form of low-affinity platelet factor 4 and betathromboglobulin. Biochemistry. 25:1988-1996.

21. Castor, C. W., J. W. Miller, and D. A. Walz. 1983. Structural and biological characteristics of connective tissue activating peptide (CTAP-III), a major human platelet-derived growth factor. Proc. Natl. Acad. Sci. USA. 80:765-769.

22. Deuel, T. F., P. S. Keim, M. Farmer, and R. L. Heinrikson. 1977. Amino acid sequence of human platelet factor 4. Proc. Natl. Acad. Sci. USA. 74:2256-2258.

23. Wolpe, S. D., B. Sherry, D. Juers, G. Davatelis, R. W. Yurt, and A. Cerami. 1989. Identification and characterization of macrophage inflammatory protein 2. Proc. Natl. Acad. Sci. USA. 86:612-616.

24. Begg, G. S., D. S. Pepper, C. N. Chesterman, and F. J. Morgan. 1978. Complete covalent structure of human beta-thromboglobulin. Biochemistry. 17:1739-1744.

25. Walz, A., and M. Baggiolini. 1989. A novel cleavage product of beta-thromboglobulin formed in cultures of stimulated mononuclear cells activates human neutrophils. Biochem. Biophys. Res. Commun. 159:969-975.

26. Luster, A. D., J. C. Unkeless, and J. V. Ravetch. 1985. Gamma-interferon transcriptionally regulates an early-response gene containing homology to platelet proteins. Nature (Lond.). 315:672676.

27. Anisowicz, A., L. Bardwell, and R. Sager. 1987. Constitutive overexpression of a growth-regulated gene in transformed Chinese hamster and human cells. Proc. Natl. Acad. Sci. USA. 84:7188-7192.

28. Richmond, A., E. Balentien, H. G. Thomas, G. Flaggs, D. E Barton, J. Spiess, R. Bordoni, U. Francke, and R. Derynck. 1988. Molecular characterization and chromosomal mapping of melanoma growth stimulatory activity, a growth factor structurally related to beta-thromboglobulin. EMBO. (Eur. Mol. Biol. Organ.) J. 7:20252033.

29. Peveri, P., A. Walz, B. Dewald, and M. Baggiolini. 1988. A novel neutrophil-activating factor produced by human mononuclear phagocytes. J. Exp. Med. 167:1547-1559.

30. Wolpe, S. D., G. Davatelis, B. Sherry, B. Beutler, D. G. Hesse, H. T. Nguyen, L. L. Moldawer, C. F. Nathan, S. F. Lowry, and A. Cerami. 1988. Macrophages secrete a novel heparin-binding protein with inflammatory and neutrophil chemokinetic properties. J. Exp. Med. 167:570-581.

31. Brown, K. D., S. M. Zurawski, T. R. Mosmann, and G. Zurawski. 1989. A family of small inducible proteins secreted by leukocytes are members of a new superfamily that includes leukocyte and fibroblast-derived inflammatory agents, growth factors, and indicators of various activation processes. J. Immunol. 142:679-687.

32. Furutani, Y., H. Nomura, M. Notake, Y. Oyamada, T. Fukui, M. Yamada, C. G. Larsen, J. J. Oppenheim, and K. Matsushima. 1989. Cloning and sequencing of the cDNA for human monocyte chemotactic and activating factor (MCAF). Biochem. Biophys. Res. Commun. 159:249-255.

33. Robinson, E. A., T. Yoshimura, E. J. Leonard, S. Tanaka, P. R. Griffin, J. Shabanowitz, D. F. Hunt, and E. Appella. 1989. Complete amino acid sequence of a human monocyte chemoattractant, a putative mediator of cellular immune reactions. Proc. Natl. Acad. Sci. USA. 86:1850-1854.

34. Thelen, M., P. Peveri, P. Kernen, V. von Tscharner, A. Walz, and M. Baggiolini. 1988. Mechanism of neutrophil activation by NAF, a novel monocyte-derived peptide agonist. FASEB (Fed. Am. Soc. Exp. Biol.) J. 2:2702-2706. 
35. Dewald, B., M. Thelen, and M. Baggiolini. 1988. Two transduction sequences are necessary for neutrophil activation by receptor agonists. J. Biol. Chem. 263:16179-16184.

36. Samanta, A. K., J. J. Oppenheim, and K. Matsushima. 1989. Identification and characterization of specific receptors for monocytederived neutrophil chemotactic factor (MDNCF) on human neutrophils. J. Exp. Med. 169:1185-1189.

37. Besemer, J., A. Hujber, and B. Kuhn. 1989. Specific binding, internalization, and degradation of human neutrophil activating factor by human polymorphonuclear leukocytes. J. Biol. Chem. In press.

38. Koo, C., R. J. Lefkowitz, and R. Snyderman. 1982. The oligopeptide chemotactic factor receptor on human polymorphonuclear leukocyte membranes exists in two affinity states. Biochem. Biophys. Res. Commun. 106:442-449.

39. Williams, L. T., R. Snyderman, M. C. Pike, and R. J. Lefkowitz. 1977. Specific receptor sites for chemotactic peptides on human polymorphonuclear leukocytes. Proc. Natl. Acad. Sci. USA. 74:12041208.

40. Hugli, T. E. 1984. Structure and function of the anaphylatoxins. Springer. Semin. Immunopathol. 7:193-219.

41. Schreiber, R. D. 1984. The chemistry and biology of complement receptors. Springer. Semin. Immunopathol. 7:221-249.

42. Dahinden, C. A., J. Kurimoto, M. Baggiolini, B. Dewald, and A. Walz. 1989. Histamine and sulfidoleukotriene release from human basophils: different effects of antigen, anti-IgE, C5a, f-Met-Leu-Phe, and the novel neutrophil-activating peptide NAF. Int. Arch. Allergy Appl. Immunol. In press.

43. Colditz, I., R. Zwahlen, B. Dewald, and M. Baggiolini. 1989. In vivo inflammatory activity of neutrophil-activating factor, a novel chemotactic peptide derived from human monocytes. Am. J. Pathol. 134:755-760.

44. Van Damme, J., J. Van Beeumen, G. Opdenakker, and A. Billiau. 1988. A novel, NH2-terminal sequence-characterized human monokine possessing neutrophil chemotactic, skin-reactive, and granulocytosis-promoting activity. J. Exp. Med. 167:1364-1376.

45. Strieter, R. M., S. H. Phan, H. J. Showell, D. G. Remick, J. P. Lynch, M. Genord, R. M. Marks, and S. L. Kunkel. 1989. Monokineinduced neutrophil chemotactic factor gene expression in human fibroblasts. J. Biol. Chem. In press.

46. Kunkel, S. L., R. M. Strieter, S. W. Chensue, and D. G. Remick. 1989. Regulation of tumor necrosis factor-alpha and neutrophil activating protein-1 gene expression: potential role of cytokine directed cell communication during multiple organ injury. In Respiratory Distress Syndrome: Molecular to Man. K. Bringham and M. Stahlmann, editors. Vanderbilt Press, Nashville, TN. In press.

47. Yoshimura, T., K. Matsushima, J. J. Oppenheim, and E. J. Leonard. 1987. Neutrophil chemotactic factor produced by lipopolysaccharide (LPS)-stimulated human blood mononuclear leukocytes: partial characterization and separation from interleukin 1 (IL 1). $J$. Immunol. 139:788-793.

48. Dixit, V. M., S. L. Kunkel, V. Sarma, R. M. Strieter, H. J. Showell, P. A. Ward, and R. M. Marks. 1989. Molecular cloning of an endothelial derived neutrophil chemotactic factor: identity with monocyte derived factor. FASEB (Fed. Am. Soc. Exp. Biol.) J. 3:A305.

49. Strieter, R. M., S. L. Kunkel, H. J. Showell, and R. M. Marks. 1988. Monokine-induced gene expression of a human endothelial cell-derived neutrophil chemotactic factor. Biochem. Biophys. Res. Commun. 156:1340-1345.

50. Schroeder, J. M., and E. Christophers. 1989. Secretion of novel and homologous neutrophil-activating peptides by LPS-stimulated human endothelial cells. J. Immunol. 142:244-251.

51. Strieter, R. M., S. L. Kundel, H. J. Showell, G. D. Remick, S. H. Phan, P. A. Ward, and R. M. Marks. 1989. Endothelial cell gene expression of a neutrophil chemotactic factor by TNF, IL-1 and LPS. Science (Wash. DC). 243:1467-1469.
52. Kunkel, S. L., M. Spengler, M. A. May, R. Spengler, J. Larrick, and D. Remick. 1988. Prostaglandin E2 regulates macrophage-derived tumor necrosis factor gene expression. J. Biol. Chem. 263:5380-5384.

53. Schroeder, J. M., and E. Christophers. 1986. Identification of C5ades arg and an anionic neutrophil-activating peptide (ANAP) in psoriatic scales. J. Invest. Dermatol. 87:53-58.

54. Watson, M. L., J. Westwick, N. J. Fincham, and R. D. Camp. 1988. Elevation of PMN cytosolic free calcium and locomotion stimulated by novel peptides from IL-1-treated human synovial cell cultures. Biochem. Biophys. Res. Commun. 155:1154-1160.

55. Baggiolini, M., J. Schnyder, U. Bretz, B. Dewald, and W. Ruch. 1979. Cellular mechanisms of proteinase release from inflammatory cells and the degradation of extracellular proteins. Ciba Found. Symp. 75:105-121.

56. Hunninghake, G. W., J. E. Gadek, T. J. Lawley, and R. G. Crystal. 1981. Mechanisms of neutrophil accumulation in the lungs of patients with idiopathic pulmonary fibrosis. J. Clin. Invest. 68:259269.

57. Rola Pleszczynski, M., S. Gouin, and R. Begin. 1984. Asbestos-induced lung inflammation: role of local macrophage-derived chemotactic factors in accumulation of neutrophils in the lungs. Inflammation. 8:53-62.

58. McGuire, W. W., R. G. Spragg, A. B. Cohen, and C. G. Cochrane. 1982. Studies on the pathogenesis of the adult respiratory distress syndrome. J. Clin. Invest. 69:543-553.

59. Idell, S., U. Kucich, A. Fein, F. Kueppers, H. L. James, P. N. Walsh, G. Weinbaum, R. W. Colman, and A. B. Cohen. 1985. Neutrophil elastase-releasing factors in bronchoalveolar lavage from patients with adult respiratory distress syndrome. Am. Rev. Respir. Dis. 132:1098-1105.

60. Parsons, P. E., A. A. Fowler, T. M. Hyers, and P. M. Henson. 1985. Chemotactic activity in bronchoalveolar lavage fluid from patients with adult respiratory distress syndrome. Am. Rev. Respir. Dis. 132:490-493.

61. Cohen, A. B., C. MacArthur, S. Idell, R. Maunder, T. Martin, C. A. Dinarello, D. Griffith, and J. McLarty. 1988. A peptide from alveolar macrophages that releases neutrophil enzymes into the lungs in patients with the adult respiratory distress syndrome. Am. Rev. Respir. Dis. 137:1151-1158.

62. Romson, J. L., B. G. Hook, S. L. Kunkel, G. D. Abrams, M. A. Schork, and B. R. Lucchesi. 1983. Reduction of the extent of ischemic myocardial injury by neutrophil depletion in the dog. Circulation. 67:1016-1023.

63. Teir, H., T. Rytomaa, A. Cederberg, and K. Kiviniemi. 1963. Studies on the elimination of granulocytes in the intestinal tract in rat. Acta Pathol. Microbiol. Scand. 59:311-324.

64. Bevilacqua, M. P., J. S. Pober, M. E. Wheeler, R. S. Cotran, and M. A. Gimbrone, Jr. 1985. Interleukin 1 acts on cultured human vascular endothelium to increase the adhesion of polymorphonuclear leukocytes, monocytes, and related leukocyte cell lines. J. Clin. Invest. 76:2003-2011.

65. Pohlman, T. H., K. A. Stanness, P. G. Beatty, H. D. Ochs, and J. M. Harlan. 1986. An endothelial cell surface factor(s) induced in vitro by lipopolysaccharide, interleukin 1 , and tumor necrosis factoralpha increases neutrophil adherence by a CDw18-dependent mechanism. J. Immunol. 136:4548-4553.

66. Detmers, P. A., E. Olsen-Egbert, P. Peveri, A. Walz, M. Baggiolini, and Z. A. Cohn. 1989. Neutrophil activating factor (NAF) enhances the binding activity of CD11b/CD18. FASEB (Fed. Am. Soc. Exp. Biol.) J. 3:A1087.

67. Dahinden, C. A., J. Kurimoto, A. L. De Weck, I. Lindley, B. Dewald, and M. Baggiolini. 1989. The neutrophil-activating peptide NAF/NAP-1 induces histamine and leukotriene release by interleukin 3-primed basophils. J. Exp. Med. In press. 